\title{
Effect of NMDA Receptor Agonist and Antagonist on Spermatogonia Stem Cells Proliferation in 2- and 3- Dimensional Culture Systems
}

\section{Amir Hessam Eskafi Noghani}

University of Tabriz

Reza Asadpour ( $\square$ rasadpour4@gmail.com )

University of Tabriz https://orcid.org/0000-0003-4717-9952

Adel Saberivand

University of Tabriz

Zohreh Mazaheri

Institute of Basic Medical Sciences

Gholamreza Hamidian

University of Tabriz

\section{Research Article}

Keywords: NMDARs, Spermatogonia stem cells, Two-dimensional culture system, Three-dimensional culture system

Posted Date: August 30th, 2021

DOI: https://doi.org/10.21203/rs.3.rs-840124/v1

License: (c) (1) This work is licensed under a Creative Commons Attribution 4.0 International License. Read Full License 


\section{Abstract}

The main purpose of this study was to investigate the effect of D-serine (DS) and Dizocilpine (MK-801or $\mathrm{Mk}$ ) on the proliferation of SSCs in two-dimensional (2D) and three-dimensional (3D) culture systems. The SSCs of male NMRI mice were isolated by enzymatic digestion and cultured for two weeks. Then, the identity of SSCs was confirmed by anti-PIzf and anti-GFR-a1 antibodies via immunocytochemistry (ICC). The proliferation capacity of SSCs was evaluated by their culture on a layer of the decellularized testicular matrix (DTM) prepared from mouse testis, as well as two-dimensional (2D) with different mediums. After two weeks of the initiation of proliferation culture on 3D and 2D medium, the pre-meiotic at the mRNA and protein levels were evaluated via qRT-PCR and flow cytometry methods, respectively.

The results showed that the proliferation rate of SSCs in three-dimensional culture with $50 \mathrm{mM}$ glutamic acid and $20 \mathrm{mM} \mathrm{D}$-serine was significantly different from other groups after 14 days treatment. mRNA expression levels of Plzf in 3D-cultures supplemented by $20 \mathrm{mM}$ D-serine and $50 \mathrm{mM}$ glutamic acid were considerably higher than the 3D control group $(p<0.001)$. The flow cytometry analysis revealed that the amount of Plzf in the 2D-culture groups of SSCs with 20mM MK-801 was considerably lower compared to the $2 D$-culture control group $(p<0.001)$. This study indicated that decellularized testicular matrix supplemented with $D$-serine and glutamic acid could be considered a promising vehicle to support cells and provide an appropriate niche for the proliferation of SSCs.

\section{Introduction}

Spermatogonia Stem Cells (SSCs) in the testis have self-renewal, proliferation, and differentiation capacities and provide a spermatogenesis process in the seminiferous tubules [1]. The process of spermatogenesis is impaired by chemotherapeutic agents and radiotherapy procedures in cancer patients [2]. Therefore, in these patients, obtaining cells from testicular tissue and the in-vitro proliferation of SSCs are critical steps to enhance the rate of SSC transplantation in patients [3]. The most critical issue for the proliferation of in-vitro SSCs is to have an environment close to the microenvironment of seminiferous tubules [4]. Some experiments indicated that three-dimensional (3D) culture systems provide an appropriate niche for cells, like seminiferous tubules [5]. Recently, DTM hydrogel scaffold introduces a different approach to the study of SSCs which improves cell-to-cell connectivity and facilitates the propagation of SSCs $[6,7]$.

$\mathrm{N}$-methyl d-aspartate type glutamate receptor (NMDAR) is an ionotropic receptor consisting of two obligatory GluN1(NR1) subunits, with high binding affinity and agonist effect of glycine or D-serine combined with two subunits of GluN2 and / or two GluN3 subunits that all bind glutamate [8]. Recent studies indicated that several subtypes of ionotropic glutamate receptor (GluRs) are expressed in rat testis [9]. NMDARs were found in germinal epithelium and interstitial spaces [10,11]. Previous studies have revealed that the agonist NMDA subtype of glutamate receptors directly affects spermatogonia mitotic activity [10, 12], spermatogonia proliferation [13], and spermatozoa maturation via the modulation of testosterone and estrogen amounts in the epididymis [14]. 
Recently, the D-amino acids were detected in various types of testis cells, including Sertoli cell, Leydig cell, spermatogonia, spermatid, and spermatozoa $[15,16]$. It was reported D-serine plays a key role in brain tissue physiology [17], cell development, and cell death signaling [18]. D-serine binds to the NMDA subtype of glutamate receptors and acts like D-aspartate on the hypothalamic-pituitary axis or directly on testicular Leydig cells and promotes testosterone synthesis [13]. Moreover, D-serine may upregulate spermatogenesis by enhancing the activity of NMDA receptors [12].

Dizocilpine (MK-801) is a non-competitive glutamate receptor antagonist which affects the central nervous system. MK-801-induced schizophrenia models describe injuries in the testis in response to reactive oxygen species (ROS) [19]. Moreover, it was shown testosterone declines after the blockade of NMDA receptors by a noncompetitive NMDA receptor antagonist (MK-801), and it is attributed to the reduction of sperm motility [9].

Consequently, cell-scaffold interaction may enhance the cell survival rate. Since there is no available data on the proliferative effect of agonists NMDA receptors on SSCs. The main purpose of this study was to investigate the effect of D-serine (DS) and Dizocilpine (MK-801or Mk) on the proliferation of SSCs in two-dimensional (2D) and three-dimensional (3D) culture systems.

\section{Materials And Methods}

\section{Animals and Drugs}

Male Naval Medical Research Institute [NMRI) mice were used in this examination. The animals were obtained from Animal Resources Department, University of Tabriz (Tabriz, Iran). The mice were kept in animal houses under standard conditions (at $22 \pm 2{ }^{\circ} \mathrm{C}$ room temperature, $50-55 \%$ humidity, light / dark cycles: 12/12 hours per day). The chemicals that were used in this study were purchased from SigmaAldrich unless otherwise mentioned.

\section{Testis dissociation and SSCs isolation}

Ten male NMRI mice ( 6 days old; $n=10$ ) were euthanized with intraperitoneal injection $100 \mathrm{mg} / \mathrm{Kg}$ ketamine and $10 \mathrm{mg} / \mathrm{Kg}$ xylazine. Their testis was removed and placed into a petri dish containing culture medium and antibiotic. Testicular tissue cells were isolated with slight modifications according to the methods presented by [20]. In summary, after washing the testicular tissue several times in PBS solution for cell isolation, the testicular capsule was removed, and then the testicular tissue was divided into approximately $1 \mathrm{~mm}^{3}$ using the mechanical procedure. Thereafter, the dissociated tissues were placed in a solution containing trypsin $(0.5 \mathrm{mg} / \mathrm{ml}$, Sigma-Aldrich, St Louis, MO, USA), collagenase I (0.5 $\mathrm{mg} / \mathrm{mL}$ Sigma-Aldrich, St Louis, MO, USA), and hyaluronidase $(0.5 \mathrm{mg} / \mathrm{mL}$, Sigma-Aldrich, St Louis, MO, USA). Then, a cell was centrifuged (1500 rpm for $5 \mathrm{~min}$ ) and washed in DMEM/F12 (Gibco, Grand Island, NY, USA) medium. Finally, the next digestion was accomplished for $15 \mathrm{~min}$ in a solution containing collagenase I (1 mg/mL, Sigma-Aldrich, St Louis, MO, USA) DNase $(0.5 \mathrm{mg} / \mathrm{mL}$ Sigma-Aldrich, St Louis, 
MO, USA,), and hyaluronidase $\left(1.5 \mathrm{mg} / \mathrm{mL}\right.$, Sigma-Aldrich, St Louis, MO, USA) in the water bath at $37^{\circ} \mathrm{C}$. The obtained cells were washed and prepared for culture after passing via a $70 \mu \mathrm{m}$ cell strainer.

\section{SSCs culture and proliferation}

After enzymatic digestion, cell viability was evaluated with $0.4 \%$ trypan blue solution in a 6-well plate with the culture medium DMEM/F12 containing 10\% FBS (Gibco, Grand Island, NY, USA) with penicillin $(100 \mathrm{U} / \mathrm{mL})$ and streptomycin $(100 \mu \mathrm{g} / \mathrm{mL}$; Gibco, Grand Island, NY, USA). To isolate the SSCs which usually attach to the bottom of the culture dish later than the somatic cells, the supernatant was removed after 24 hours and centrifuged (1000 rpm for 5 minutes) to separate the non-attached cells. Then cells were cultured in DMEM/F12 medium containing $5 \%$ Knockout serum replacement (KSR) (Gibco, Grand Island, NY, USA) GDNF (10ng/mL, Sigma Alderich St.Louis.MO, USA), LIF (1030 U/mL, Sigma Alderich St.Louis.MO, USA) EGF (20ng/mL, Sigma Alderich St.Louis.MO, USA) bFGF (10ng/mL, Sigma Alderich St.Louis.MO, USA) in gelatin ( $0.2 \%$; Sigma Alderich St.Louis.MO, USA) coated dishes, and then incubated at $35^{\circ} \mathrm{C}$ in a humidified atmosphere with $5 \% \mathrm{CO}_{2}$. The medium replaces every $48 \mathrm{~h}$. After two weeks since the initial culture, SSCs colonies were observed. After two weeks in culture, the Plzf protein was traced as a positive marker to confirm the identity of the colonies derived from the SSCs [21].

\section{Immunocytochemistry for characterization of SSCs colonies}

To characterize SSC colonies, Plzf expression was determined by immunocytochemistry (ICC). After fixation with paraformaldehyde (4\%) permeability with $0.4 \%$ Triton X100 (Sigma-Aldrich, St Louis, MO, USA) and blocking with $10 \%$ goat serum (Sigma-Aldrich, St Louis, MO, USA), cells were treated with rabbit polyclonal antibody anti-PIzf (sc28319;mouse monoclonal, 1:500, Santa Cruz, Houston, USA) and antiGFR-a1 (pa519873;Rabbit polyclonal, 1:100, Thermo Fisher, Altrincham, UK) for $2 \mathrm{~h}$ at $37^{\circ} \mathrm{C}$. After washing with PBS, a secondary antibody, Donkey Anti-Rabbit, labeled with fluorescent isothiocyanate (FITC) 1: 100 (Sigma-Aldrich, St Louis, MO, USA), was added for $3 \mathrm{~h}$. Control cells were treated under similar conditions except for the removal of primary antibodies. The nuclei were stained with 4,6diamidino-2-phenylindole (DAPI, $1 \mu \mathrm{g} / \mathrm{mL}$; Sigma-Aldrich, St Louis, MO, USA) [22].

\section{Tissue decellularization}

In this experimental study, testicular scaffolds were generated using the testes obtained from 6 mice models (6-8 weeks old). The tunica albuginea was removed from the testes of the mice using a 29-gage insulin syringe and washed with phosphate buffer saline [PBS, Sigma, USA) to remove the residual blood. The sections of $100 \mu \mathrm{m}$ diameters of testis were immersed in $\% 0.5(\mathrm{v} / \mathrm{v})$ of sodium dodecyl sulfate (SDS, Sigma-Aldrich, St Louis, MO, USA) and \% 0.5 (v/v) triton X-100 (TX-100; Sigma-Aldrich, St Louis, MO, USA) and then incubated for $18 \mathrm{~h}$ in water. Then, they were placed by PBS for $2 \mathrm{~h}$ to remove detergents. After washing, the decellularized tissue sections were sterilized in 70\% ethanol for 1 hour and immersed in PBS for 2 hours. Before usage, the scaffolds were immersed in a culture medium for 24 hours [23].

\section{Histological examination}


Hematoxylin-eosin (H\&E) staining was used to confirm the quality of DTM and evaluate cell migration to the scaffold after its recellularization. Each sample was fixed in formaldehyde [10\%), dehydrated through increasing ethanol concentration, after clearing by xylen and embedding in paraffin, $5-\mu \mathrm{m}$ thick sections were prepared with a microtome (Leica, Germany). Sections were deparaffinized, rehydrated, and stained via Hematoxylin \& eosin (all from Merck Germany). Alcian blue staining (Merck, Germany) was conducted to assess the amount of glycosaminoglycan's (GAGs) based on previous described protocols [24]. Masson's Trichrome staining was performed according to guidelines to determine the existence of collagen [25]. Slides were observed under a light microscope (Labomed, USA), and images (nuclei are stained dark blue, cytoplasm are stained bright-red, as well as collagen is stained green or blue) were taken with a Ziess Camera.

\section{DAPI staining for nuclei staining of decellularized tissue}

Both confirmed the intact and decellularization of the testis by 4, 6-diamidino-2-phenylindol (DAPI) staining and DNA quantification. To assess the homogeneity of decellularization, the samples were collected from different sites of the scaffolds. In brief, DAPI solution $(1 \mu \mathrm{g} / \mathrm{mL}$; Sigma-Aldrich, St Louis, MO, USA) was pipetted directly to each tissue section after fixing the tissues in formalin. They were kept in the dark room for $15 \mathrm{~min}$. After washing with PBS, the samples were evaluated with an inverted fluorescence microscope.

\section{DNA content in decellularized testicular tissue}

For quantitative testing, the total amount of DNA from native tissue and decellularized testicular scaffold were extracted by a genomic DNA purification kit (Qiagen, UK). The purity and concentration of DNA were calculated by Nanodrop spectrophotometers (UV-visible; Thermo Nanodrop ND-1000) at $260 \mathrm{~nm}$ and agarose gel [24].

\section{Synthesis of dual-crosslinked hydrogels: Natural ECM of decellularized testis and Hyaluronic acid hydrogel}

For composite-cross-linked hydrogels, $10 \mathrm{mg}$ of sodium hyaluronate powder was dispensed into a circular silicone rubber mold. The same volume of lyophilized testicular tissue extract was sandwiched between two rubber molds and tightly secured. Crosslinking solutions consisted of $0.2 \mathrm{M} \mathrm{NaOH}$ containing butanediol diglycidyl ether (BDDE). The concentration of cross linkers was measured in units of $\mu \mathrm{LBDDE} / \mathrm{g} \mathrm{HA}$ [25]. This fluid was inserted into each rubber mold by a syringe equipped with a 25gage needle. A second needle created an air escape, and caution was considered to stop bubble trapping. A volume of crosslinking fluid was applied to fill each mold. Molds were roughly $100 \mu \mathrm{L}$ in volume and had an HA concentration of $10 \%$. HA and crosslink solution were then incubated at $40^{\circ} \mathrm{C}$ for $8 \mathrm{~h}$. The cross-linked hydrogels were separated from the molds and relocated to a large amount of distilled deionized water or saline $(0.9 \% \mathrm{NaCl})$ for swelling. 
Following the scaffold was produced, its toxicity was tested to confirm that it did not contain any hazardous substances during the scaffold preparation and decellularization stages. After the culture of SSCs at a concentration of $5 \times 10^{4}$ in each well of 96-well plate, scaffold extract was added to cells in the culture medium, and after $24 \mathrm{~h}, 48 \mathrm{~h}$, and $72 \mathrm{~h}$ since the inception of the culture, the cell was evaluated using 3-(4,5-Dimethylthiazol-2-yl)-2,5-diphenyltetrazolium bromide (MTT). In brief, add $200 \mu \mathrm{l}$ of MTT solution $(0.5 \mathrm{ng} / \mathrm{ml})$ to each well and incubated for $4 \mathrm{~h}$ at $37{ }^{\circ} \mathrm{C}$ in a humidified atmosphere $5 \% \mathrm{CO}_{2}$ incubator, and after that, cells lysed and purple formazan crystal dissolved by adding $400 \mu \mathrm{L}$ of DMSO (D8418, Sigma-Aldrich, St Louis, MO, USA) in each well for $30 \mathrm{~min}$ at room temperature. Finally, the purple formazan formed during the test step was measured at $540 \mathrm{~nm}$ with the microplate reader [1].

\section{Scanning electron microscopy (SEM)}

Scanning electron microscopy (SEM) evaluated the 3D structure of scaffold, quality, decellularization, and cell migration after recellularization. The tissues were fixed with $2.5 \%$ glutaraldehyde for $2 \mathrm{~h}$, and then with $1 \%$ osmium tetroxide and dewatering by increasing the degrees of ethanol (30 to $100 \%$ ). After dehydration, the tissues were placed on a grid, covered with a gold-palladium coating, and seen via SEM (FEl Quanta 200). The number and diameter of SSCs colonies in each field and pores size of the scaffold were analyzed using SEM [26].

\section{Preparation of DTM and Reconstitution of testicular cells on it}

Reconstituted testicular artificial tissue using a hyaluronic gel matrix $2 \%$ and $50 \mathrm{mg}$ of Decellularized testes extract ( $1: 1 \mathrm{v} / \mathrm{v}$ ratio) were placed in a 24 -well culture dish in a thin layer form. Then, $1 \times 10^{5}$ cells were added to each well plate (Nunc, Roskilde, Denmark) to which collagen gel matrix and somatic cells adhere poorly. After gently agitating the gels for 1 minute, they were overlaid with DMEM/F12 medium supplemented with $5 \% \mathrm{KSR}, 5 \% \mathrm{FBS}$. During culture, the period medium was replaced every 2 days. After two weeks of culture, the matrix gel was re-dissolved with $0.25 \%$ trypsin to release the embedded cells, and then cell viability and proliferation were determined after two weeks of initiation of culture [25].

\section{Experimental Design}

The culture groups were classified into 2 categories include (1) 2D culture and (2) 3D culture. Each group were defined in a subgroup with different treatments include 1a (2D-D-Serine) or 2a (3D- D-Serine); DSerine treatment, 1b [2D- Glutamic acid) or 2b (3D- Glutamic acid); Glutamic acid, 1c (2D-MK-801) or 2c; MK-801 (3D- MK-801). D-Serine and MK-801 were used $20 \mu \mathrm{M}$, and Glutamic acid was used $50 \mu \mathrm{M}$ in a final concentration. SSCs cultured in each experimental group for 2 weeks for assessment of SSCs proliferation in different culture medium situations. Two normal groups included 2D and 3D without Dserine, and MK-801 were designed as control groups in the whole study phases.

\section{Gene expression analysis}


In the second weeks of proliferation culture, the total RNA of the cells cultured in 2D and 3D culture was extracted using guanidine / phenol solution (Qiazol-Qiagene USA). Then RNA was treated with DNase I (Fermentase, USA) to eliminate genomic contamination. The purity and concentration of RNA were determined using Nano Drop 2000 (Thermo scientific). For Complementary DNA (cDNA) synthesis, $1 \mu \mathrm{g}$ total RNA was carried out by reverse transcription kit, using a Prime Script RT reagent kit (Hyper script RTPCR- GeneAll) according to the manufacture instructions. PCR was carried out using mixed Master Mix and SYBR green in the stage one of thermal cycle (ABI stage one, USA). PCR program began with melting cycle of $15 \mathrm{~min}$ at $95^{\circ} \mathrm{C}$. The stage was followed by 40 cycles: initial denaturation $30 \mathrm{~s}$ at $95^{\circ} \mathrm{C}$, annealing $30 \mathrm{~s}$ at $60^{\circ} \mathrm{C}$, and extension $30 \mathrm{~s}$ at $60^{\circ} \mathrm{C}$. The specific primers used to determine the expression levels of pre-meiotic genes including PIzf [Forward: 5' AGT GGG ATT GAT GAG GAG ATG G 3' and Reverse 5' AGT GGA GTG TAG GGA GAA GGA 3') as SSCs specific markers and ßactin (Forward 5' TCA GAG CAA GAG AGG CAT CC 3'and Reverse: 5' GGT CAT CTTCTC ACG GTT GG 3') as internal control gene. To investigate the presence of non-specific products and primer dimers, a melting curve analysis was performed. Furthermore, this process was replicated in triplicates for target and reference genes. All samples were normalized to the Bactin as a reference gene using $(\Delta \Delta C T)$ method [27].

\section{Protein evaluation by Flow cytometry}

The process of cell staining for flow cytometry was done based on pervious researchers by Kanatsu et al. [28]. Furthermore, the cells fixed at $4 \%$ paraformaldehyde and permeabilized at $0.5 \%$ Triton X-100 (Invitrogen, UK) for 5 minutes before being blocked by a combination of $10 \%$ goat serum and Bovine serum albumin [BSA, $1 \mathrm{mg} / \mathrm{ml}$ ). The incubation of cells was performed with the primary antibodies, including rabbit anti $P / z f$ at $4^{\circ} \mathrm{C}$ overnight. Cells were incubated with a certain number of secondary antibodies (FITC, conjugated goat anti rabbit IgG) $60 \mathrm{~min}$ at $37^{\circ} \mathrm{C}$ in the dark. After washing with PBS, flow cytometric analysis was accomplished with a Becton Dickinson (BD) and was analyzed with Flowjo 7.6 software.

\section{Statistical analysis}

The data presented are expressed as mean \pm standard error (mean \pm SEM). Kolmogorov-Smirnov test was used to determine the normal distribution of data. An independent sample t-test was used for DNA content and MTT analysis. For multiple comparisons of data, One-way analysis of variance (ANOVA) followed by Tukey's test used. Graph Pad Prism software version 8 (Graph Pad Software San Diego, CA) was used for data analysis. Data with less than $<0.05$ were considered statically significant.

\section{Results}

\section{SSCs colonies characterization}

SSCs were isolated using a protocol involving two enzymatic digestion steps. SSCs proliferating colonies were observed approximately two week after obtaining the culture of cells derived from testicular tissues. The small colonies formed from them were observed in the culture medium, and the number of these 
colonies increased. To confirm the identity of SSCs, the colonies were investigated using two specific markers of SSCs (Plzf and GFRa1) via ICC staining (Fig.1 A,B ). The results showed that the majority of colonies are positive with both SSCs markers. For further confirmation, the gene expression related to SSCs was measured by qRT-PCR prior to the initiation of the differentiation phase.

\section{Evaluation of decellularization}

The first stage of analyzing the effectiveness of decellularization is to validate the removal of cellular components. The histological evaluation indicated that the cells were destroyed with SDS and Triton x100 in the testis. H\&E staining demonstrated well preserved structural architecture of the testis with no cell fragments remained in the tissue. The empty seminiferous tubules are clearly distinguishable. The total amount of glycosaminoglycans (GAGs) in Alcian blue and Masson's trichrome staining were tested and showed strong retention in decellularized testis relative to normal tissue (Fig.2,A). The remaining GAG in the scaffold was stained with Alcian blue, indicating that more than $80 \%$ of GAG remained. No significant difference was observed in decellularized testis compared to the normal $(p=0.1964)(F i g .2, C)$. The amount of DNA was measured to evaluate the efficiency of the decellularization method and compared to DNA amount in native tissue. Analyzing DNA contents showed that DNA was successfully removed from the testis compared to the normal group $(p<0.0001)$ (Fig.2, B). The pictures of the SEM assessment were showed a tubular structure in the tissue without any cells. Besides, the structure was remained normal in some parts of tissue (Fig. 2, D).

\section{Proliferation of SSC on scaffold after 14 days culture}

MTT results demonstrated that the decellularized scaffolding was non-toxic. SSCs were cultured inside the decellularized testicular scaffold, and cell viability was assessed after $24 \mathrm{~h}$ and $48 \mathrm{~h}$. The proliferation rate of SSCs in the three-dimensional culture with $50 \mathrm{mM}$ glutamic acid and $20 \mathrm{mM}$ D-serine was significantly different from the other groups after 14 days of treatment. Nevertheless, the proliferation rate of SSCs in the 3D-culture with MK-801 was significantly lower than in other groups (Fig. 3).

\section{Molecular evaluation of Plzf in 3-D cultured SSC}

Our results indicated that the expression of $P / z f$ gene in the 3D group of spermatogonia stem cell cultures with $20 \mathrm{Mm}$ D-serine and $50 \mathrm{mM}$ glutamic acid was significantly greater than the control group $(\mathrm{p}<0.001)$. The expression of desired gene in the 2D and 3D group of SSC culture with 20mM MK-801 (MK20) was, decreased compared to each of the control groups, respectively. However, the alteration in gene expression was not statistically significant ( $p=0.294, p=1.064$ respectively) (Fig. 4).

\section{Protein level PLZF marker in SSCs in different experimental groups}

The detection of germ cells at the protein level was performed via one in all experimental groups. The flow cytometric results revealed that the expression of Plzf protein in the 3D culture group of SSCs with Dserine and glutamic was substantially more than the 3D culture control group $(p<0.001)$. The expression of Plzf in the 2D culture groups of SSCs with MK-801 was lower than the 2D culture control group 
$(p<0.001)$. No significant difference was observed in the 3D culture of SSC with MK-801 compared to 3D culture control $(p=0.187)$

\section{Discussion}

For the first time, we developed the SSCs culture in the DTM hydrogel scaffold and indicated the role of Dserine, and MK-801 as the agonist and antagonist of NMDA receptors, respectively, in the spermatogenesis process. Decellularized testicular matrix [DTM) hydrogel scaffold is suitable for the surrounded SSCs and Sertoli cells to enhance the proliferation and differentiation of SSCs [29]. Our results, like previous findings, showed that the DTM hydrogel scaffold is appropriate for the proliferation of SSCs [30]. DTM hydrogel scaffolds contain laminin and collagen, which can regulate the proliferation of SSCs and so, the purity of SSCs increases [29, 31]. The other constituents of DTM are GAGs which surround the Sertoli cells and Leydig cells and affect cell adhesion, and proliferation [32]. These results showed that DTM contains some growth factors which can maintain SSCs activity and gene expression.

Moreover, this study's results revealed that the supplementation of a 3D culture medium with glutamic acid improved spermatogonia proliferation. Similar to these results, Santillo et al. revealed that the addition of glutamate to spermatogonia germ cell 1 (GC1) medium increased spermatogonia proliferation [33]. The previous study showed that glutamate-induced the phosphorylation of ERK1/2 protein in spermatogonia GC1 cells [33]. Moreover, a surge of Akt activity in spermatogonia cells treated with glutamate was observed [10]. It has already been shown that extracellular-regulated kinase (ERK1) and Akt regulate various biological functions such as gene expression and cell cycle [34, 35], and play an important role in germ cell proliferation [36]. Besides, it was declared that L-glutamine receptors are functionally expressed in rat testis which might promote stem cell proliferation by increasing glutathione levels inside and outside the cell as well as cysteine/cysteine balance $[9,37,38]$. Another mechanism is that glutamic acid stimulates the proliferation of SSCs via anti-apoptotic pathways and by increasing testosterone in Leydig cells [39].

Based on the results, we found that enriched 3D culture medium with D-serine enhances SSCs proliferation. In agreement with our results, stated that enriched media with D-serine had significantly increased the proliferation and survival of SSC [18]. On the other hand, it was indicated that treatment with D-serine increased the number of germ cells in silkworms via ERK phosphorylation in the testis [39]. After treating testes with D-serine, phosphorylated ERK was identified in spermatocytes and spermatids [40] which is consistent with an earlier finding that the meiosis of rat spermatocytes depended on the ERK activation of rat spermatocytes [41]. Furthermore, agonist NMDA receptors can stimulate the proliferation of stem cells and increase their population in culture by supporting the intracellular antioxidant glutathione synthesis and reducing intracellular ROS [42].

This study's findings revealed that the survival rate of SSCs in the 3D culture decreased after treating 3D and 2D cultures with MK-801. In line with our previous results, the experiments showed that the administration of MK-801 to rat testis resulted in increased oxidative stress in rat testis [43]. Similarly, 
Saleh et al. demonstrated that the administration of MK-801 to rabbits increased the atrophy of the tubular structure and the degeneration of germinal cells in the lumen of the seminiferous tubule in histopathological evaluation [44]. Moreover, it was reported that the level of total antioxidant status and sperm kinematics parameters have decreased following the administration of MK-801 [45, 46]. Histological data showed that using MK- 801 as antagonist NMDA, due to the testicular seminiferous tubule atrophy, degenerative changes in the epithelial cells, and a decrease in the number of the spermatozoa and necrotic [47]. MK-801 reduces SSCs proliferation by increasing ROS production and increasing the expression of Bax and Bcl2 in SSCs [18]. These results showed that the presence of Dserine alone or along with glutamic acid in the 3D culture of mouse SSCs creates a testis-like microenvironment.

\section{Conclusions}

In summary, this study indicated that the DTM hydrogel scaffold culture system provided a simple and alternative method for culturing SSCs that eliminates potential diversity and contamination caused by feeder cells. Moreover, our results showed that supplemented culture medium with $20 \mathrm{mM}$ D-serine and $50 \mathrm{mM}$ glutamic acid could be considered a promising vehicle to support cells and provide a suitable niche for the proliferation of SSCs. The results of this study could be a way to further study the process of spermatogenesis in vitro and provide novel therapeutics for a higher proliferation rate of SSCs in male infertility to achieve an acceptable SSCs number.

\section{Declarations}

\section{Acknowledgments}

This study is part of the Ph.D. thesis in the Department of Clinical Sciences, Faculty of Veterinary Medicine, University of Tabriz, and is sponsored financially by the research deputy of the University of Tabriz.

Funding This research did not receive any specific grant from funding agencies in the public, commercial, or not-for-profit sectors.

Conflicts of interest The authors have no conflicts of interest to declare which are relevant to the content of this article.

Availability of data and material The datasets generated during and/or analysed during the current study are available from the corresponding author on reasonable request.

Code availability Not applicable' for that section.

Authors' contributions Amir Hessam Eskafi Noghani: performed the research and prepared manuscript Reza Asadpour : contributed to study design, wrote the draft, and interpreted the data. AS: contributed in 
performing study and revised the manuscript Zohreh Mazaheri: contributed in the construction of 3D culture system, interpret the data, Gholamreza Hamidian: revise the manuscript and interpret histology data; all authors approved the submitted version.

Ethics approval Ethics Committee approved all experimental procedures of the University of Tabriz, Tabriz, Iran, to use animals (Permission No. IR.TABRIZU.REC.1399.045).

Consent to participate Not applicable' for that section.

Consent for publication Not applicable' for that section.

\section{References}

1. Movassagh SA, Movassagh SA, Dehkordi MB, Pourmand G, Gholami K, Talebi A et al (2020) Isolation, identification and differentiation of human spermatogonial cells on three-dimensional decellularized sheep testis. Acta Histochem 122(8):151623

2. AbuMadighem A, Solomon R, Stepanovsky A, Kapelushnik J, Shi Q, Meese E et al (2018) Development of spermatogenesis in vitro in three-dimensional culture from spermatogonial cells of busulfan-treated immature mice. Int J Mol Sci 19(12):3804

3. Sanjo H, Komeya M, Sato T, Abe T, Katagiri K, Yamanaka H et al (2018) In vitro mouse spermatogenesis with an organ culture method in chemically defined medium. PLoS One 13(2):e0192884

4. Huleihel M, Nourashrafeddin S, Plant TM (2015) Application of three-dimensional culture systems to study mammalian spermatogenesis, with an emphasis on the rhesus monkey (Macaca mulatta). Asian J Androl 17(6):972

5. Gholami K, Pourmand G, Koruji M, Ashouri S, Abbasi M (2018) Organ culture of seminiferous tubules using a modified soft agar culture system. Stem Cell Res Ther 9(1):249

6. Baert Y, Rombaut C, Goossens E (2017) Scaffold-based and scaffold-free testicular organoids from primary human testicular cells. InOrganoids Humana, New York, pp 283-290

7. Murdock MH, David S, Swinehart IT, Reing JE, Tran K, Gassei K et al (2019) Human testis extracellular matrix enhances human spermatogonial stem cell survival in vitro. Tissue Eng Part $A$ 25(7-8):663-676

8. Huang X-T, Li C, Peng X-P, Guo J, Yue S-J, Liu W et al (2017) An excessive increase in glutamate contributes to glucose-toxicity in $\beta$-cells via activation of pancreatic NMDA receptors in rodent diabetes. Sci Rep 7:44120

9. Takeshi T, Balcar Vladimir J, Hideo T (2004) Possible expression of functional glutamate transporters in the rat testis. J Endocrinol 181:233-244

10. Santillo A, Falvo S, Chieffi P, Burrone L, Chieffi Baccari G, Longobardi S et al (2014) D-aspartate affects NMDA receptor-extracellular signal-regulated kinase pathway and upregulates androgen receptor expression in the rat testis. Theriogenology 81(5):744-751 
11. Storto M, Sallese M, Salvatore L, Poulet R, Condorelli D, Dell'Albani P et al (2001) Erratum: Expression of metabotropic glutamate receptors in the rat and human testis. J Endocrinol 170(2):71-78

12. Di Fiore MM, Santillo A, Falvo S, Longobardi S, Chieffi Baccari G (2016) Molecular mechanisms elicited by D-aspartate in Leydig cells and spermatogonia. Int J Mol Sci 17(7):1127

13. Santillo A, Falvo S, Chieffi P, Di Fiore MM, Senese R, Chieffi Baccari G (2016) D-Aspartate induces proliferative pathways in spermatogonial GC-1 cells. J Cell Physiol 231:490-495

14. Falvo E, Tremante E, Arcovito A, Papi M, Elad N, Boffi A et al (2016) Improved doxorubicin encapsulation and pharmacokinetics of ferritin-fusion protein nanocarriers bearing proline, serine, and alanine elements. Biomacromol 17:514-522

15. D’Aniello G, Ronsini S, Guida F, Spinelli P, D’Aniello A (2005) Occurrence of D-aspartic acid in human seminal plasma and spermatozoa: possible role in reproduction. Fertil Steril 84(5):1444-1449

16. Sakai K, Homma H, Lee J-A, Fukushima T, Santa T, Tashiro K et al (1998) Localization ofd-Aspartic Acid in Elongate Spermatids in Rat Testis. Arch Biochem Biophys 351(1):96-105

17. Matsui Ta, Sekiguchi M, Hashimoto A, Tomita U, Nishikawa T, Wada K (1995) Functional comparison of D-serine and glycine in rodents: the effect on cloned NMDA receptors and the extracellular concentration. J Neurochem 65(1):454-458

18. Modirshanechi G, Eslampour MA, Abdolmaleki Z (2020) Agonist and antagonist NMDA receptor effect on cell fate during germ cell differentiation and regulate apoptotic process in 3D organ culture. Andrologia e13764

19. Turkmen R, Akosman MS, Demirel HH (2019) Protective effect of N-acetylcysteine on MK-801induced testicular oxidative stress in mice. Biomed Pharmacother 109:1988-1993

20. Kanatsu-Shinohara M, Ogonuki N, Inoue K, Miki H, Ogura A, Toyokuni S, Shinohara T (2003) Longterm proliferation in culture and germline transmission of mouse male germline stem cells. Biol Reprod 69(2):612-616

21. Sadri-Ardekani H, Mizrak SC, van Daalen SK, Korver CM, Roepers-Gajadien HL, Koruji M, Hovingh S, de Reijke TM, de la Rosette JJ, van der Veen F, de Rooij DG (2009) Propagation of human spermatogonial stem cells in vitro. Jama 302(19):2127-2134

22. Mahaldashtian M, Naghdi M, Ghorbanian MT, Makoolati Z, Movahedin M, Mohamadi SM (2016) In vitro effects of date palm (Phoenix dactylifera L.) pollen on colonization of neonate mouse spermatogonial stem cells. J Ethnopharmacol 186:362-368

23. Majidi Gharenaz N, Movahedin M, Mazaheri Z (2020) Three-Dimensional Culture of Mouse Spermatogonial Stem Cells Using A Decellularised Testicular Scaffold. Cell J 21(4):410-418

24. Daryabari S, Kajbafzadeh A-M, Fendereski K, Ghorbani F, Dehnavi M, Rostami M et al (2019) Development of an efficient perfusion-based protocol for whole-organ decellularization of the ovine uterus as a human-sized model and in vivo application of the bioscaffolds. J Assist Reprod Genet $36: 1211-1223$

25. Zawko SA, Suri S, Truong Q, Schmidt CE (2009) Photopatterned anisotropic swelling of dualcrosslinked hyaluronic acid hydrogels. Acta Biomater 5(1):14-22 
26. Schindelin J, Rueden CT, Hiner MC, Eliceiri KW (2015) The Image J ecosystem: An open platform for biomedical image analysis. Mol Reprod Dev 82:518-529

27. Ziloochi Kashani M, Bagher Z, Asgari HR, Najafi M, Koruji M, Mehraein F (2020) Differentiation of neonate mouse spermatogonial stem cells on three-dimensional agar/polyvinyl alcohol nanofiber scaffold. Syst Biol Reprod Med 66(3):202-215

28. Kanatsu-Shinohara M, Inoue K, Lee J, Yoshimoto M, Ogonuki N, Miki H, Baba S, Kato T, Kazuki Y, Toyokuni S, Toyoshima M (2004) Generation of pluripotent stem cells from neonatal mouse testis. Cell 119(7):1001-1012

29. Yang Y, Lin Q, Zhou C, Li Q, Li Z, Cao Z et al (2020) A testis-derived hydrogel as an efficient feederfree culture platform to promote mouse spermatogonial stem cell proliferation and differentiation. Front Cell Dev Biol 8:250

30. Topraggaleh TR, Valojerdi MR, Montazeri L, Baharvand H (2019) A testis-derived macroporous 3D scaffold as a platform for the generation of mouse testicular organoids. Biomater Sci 7(4):14221436

31. Spang MT, Christman KL (2018) Extracellular matrix hydrogel therapies: in vivo applications and development. Acta Biomater 68:1-14

32. Yang L, Li X, Wu Y, Du P, Sun L, Yu Z et al (2020) Preparation of PU/Fibrin Vascular Scaffold with Good Biomechanical Properties and Evaluation of Its Performance in vitro and in vivo. Int $\mathrm{J}$ Nanomedicine 15:8697-8715

33. Santillo A, Falvo S, Di Fiore MM, Di Giacomo Russo F, Chieffi P, Usiello A et al (2019) AMPA receptor expression in mouse testis and spermatogonial GC-1 cells: A study on its regulation by excitatory amino acids. J Cell Biochem 120(7):11044-11055

34. Cooper TG, Yeung CH, Nashan D, Nieschlag E (1988) Epididymal markers in human infertility. J Androl 9(2):91-101

35. Vogiatzi P, Giordano A (2007) Following the tracks of AKT1 gene. Cancer Biol Ther 69(10):15211524

36. Chieffi P, Chieffi S (2013) Molecular biomarkers as potential targets for therapeutic strategies in human testicular germ cell tumors: an overview. J Cell Physiol 228(8):1641-1646

37. Zhang W, Zhang K, Li G, Yan S, Cui L, Yin J (2018) Effects of large dimensional deformation of a porous structure on stem cell fate activated by poly(l-glutamic acid)-based shape memory scaffolds. Biomater Sci 6(10):2738-2749

38. Li B, He X, Zhuang M, Niu B, Wu C, Mu H et al (2018) Melatonin ameliorates busulfan-induced spermatogonial stem cell oxidative apoptosis in mouse testes. Antioxid Redox Signal 28(5):385-400

39. Hu JC-C, Zhang C, Sun X, Yang Y, Cao X, Ryu O et al (2000) Characterization of the mouse and human PRSS17 genes, their relationship to other serine proteases, and the expression of PRSS17 in developing mouse incisors. Gene 251(1):1-8

40. Suzuki C, Tanigawa M, Tanaka H, Horiike K, Kanekatsu R, Tojo M et al (2014) Effect of d-serine on spermatogenesis and extracellular signal-regulated protein kinase (ERK) phosphorylation in the testis 
of the silkworm, Bombyx mori. J Insect Physiol 67:97-104

41. Godet M, Sabido O, Gilleron J, Durand P (2008) Meiotic progression of rat spermatocytes requires mitogen-activated protein kinases of Sertoli cells and close contacts between the germ cells and the Sertoli cells. Dev Biol 315(1):173-188

42. Huang X, Kong H, Tang M, Lu M, Ding JH, Hu G (2012) D-Serine regulates proliferation and neuronal differentiation of neural stem cells from postnatal mouse forebrain. CNS Neurosci Ther 18(1):4-13

43. Parlaktas BS, Ozyurt B, Ozyurt H, Tunc AT, Akbas A (2008) Levels of oxidative stress parameters and the protective effects of melatonin in psychosis model rat testis. Asian J Androl 10(2):259-265

44. Saleh SY, Sawiress FA, Tony MA, Hassanin AM, Khattab MA, Bakeer MR (2015) Protective role of some feed additives against dizocelpine induced oxidative stress in testes of rabbit bucks. J Agric Sci 7(10):239

45. Turkmen R, Akosman MS, Demirel HH (2019) Protective effect of N-acetylcysteine on MK-801induced testicular oxidative stress in mice. Biomed Pharmacother 109:1988-1993

46. Zhang X, Wang L, Zhang X, Ren L, Shi W, Tian Y et al (2017) The use of KnockOut serum replacement (KSR) in three dimensional rat testicular cells co-culture model: An improved male reproductive toxicity testing system. Food Chem Toxicol 106:487-495

47. Ozyurt B, Ozyurt H, Akpolat N, Erdogan H, Sarsilmaz M (2007) Oxidative stress in prefrontal cortex of rat exposed to MK-801 and protective effects of CAPE. Prog Neuropsychopharmacol Biol Psychiatry 31(4):832-838

\section{Figures}


A

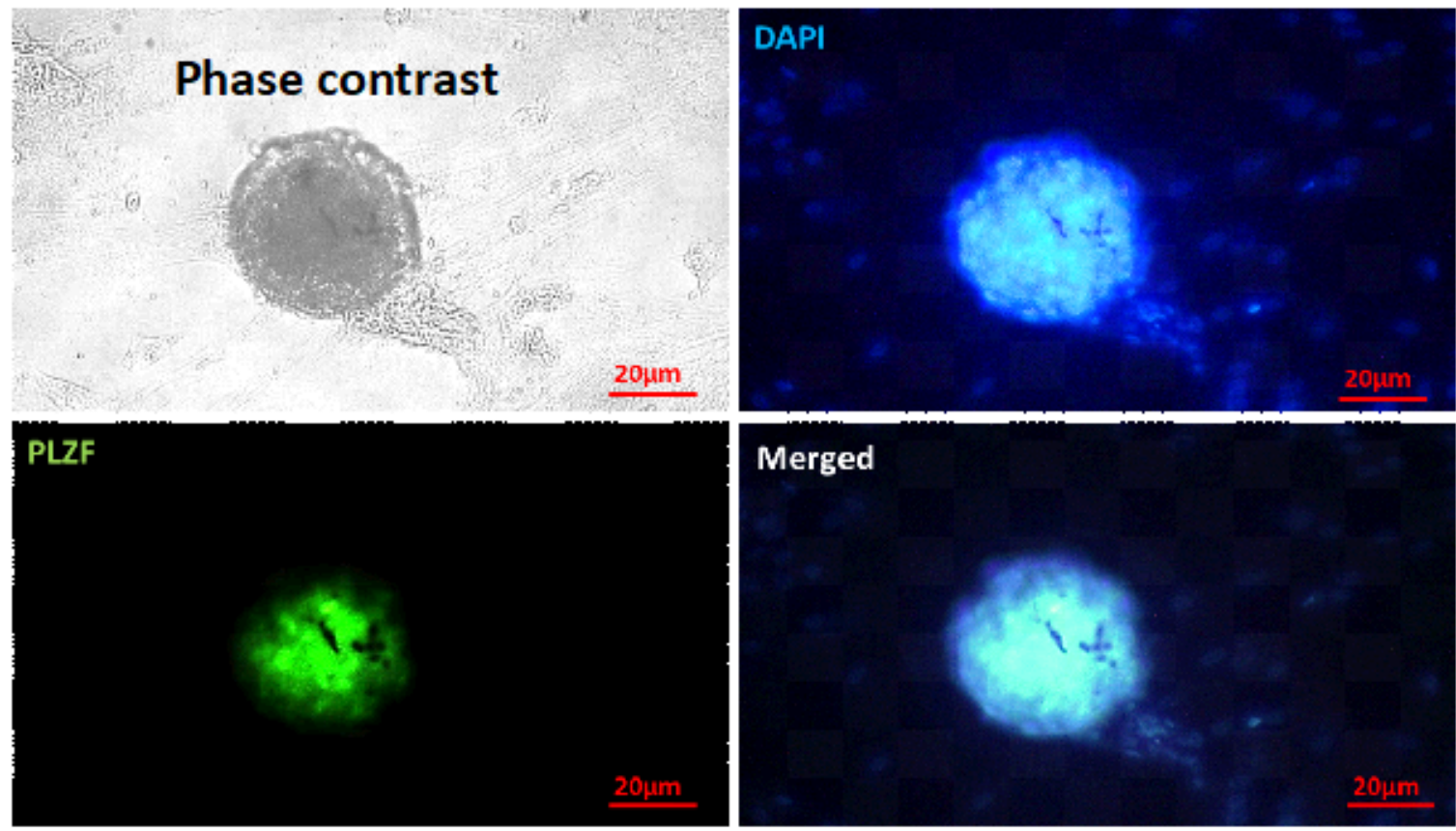

B
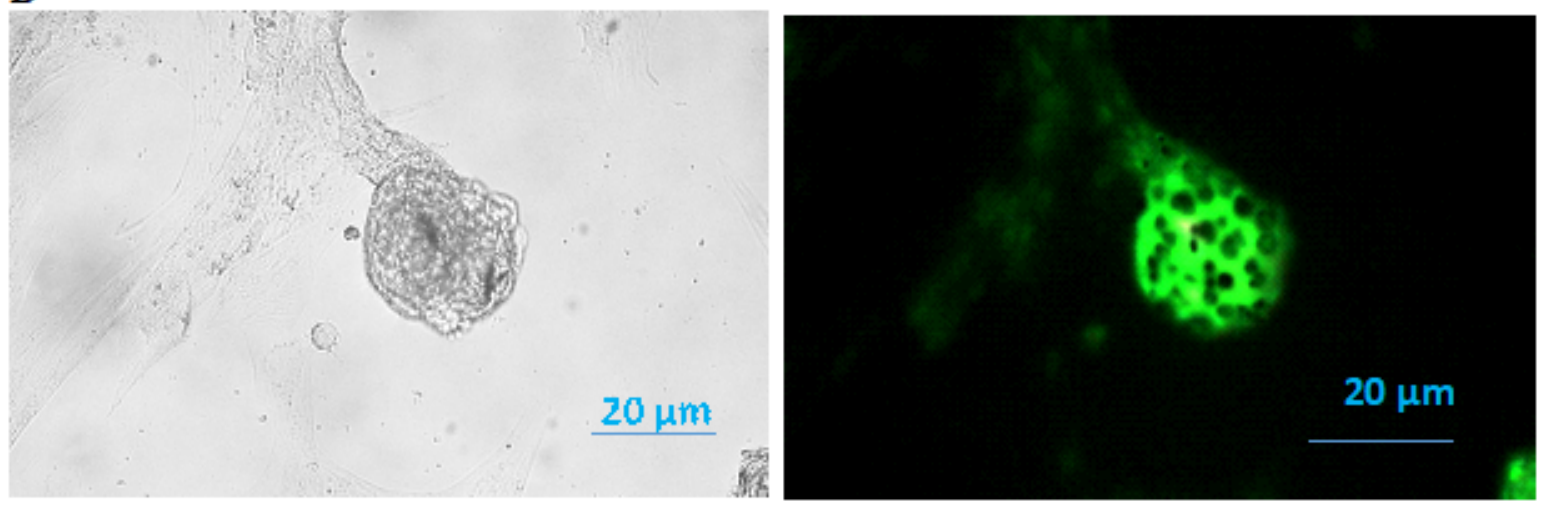

DAPI

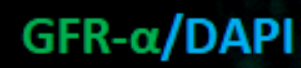

$20 \mu \mathrm{m}$

$20 \mu \mathrm{m}$

\section{Figure 1}

Characterization of SSCs formation. Phenotypic characteristics of SSCs revealed oval shape. Immunostaining of SSCs using Plzf. The ICC results indicated the presence of Plzf (A) and GFRa1 (B) under a fluorescence microscope. Nuclei are stained with DAPI. Scale bar, $20 \mu \mathrm{m}$. 


\section{A}

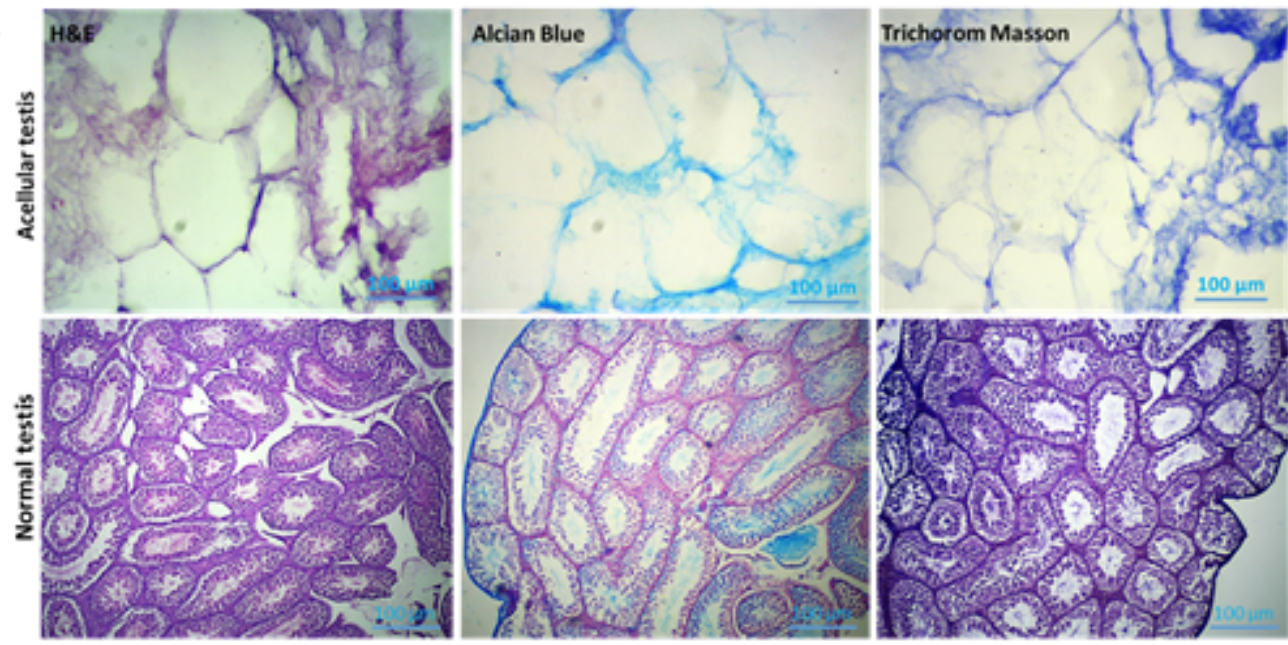

B

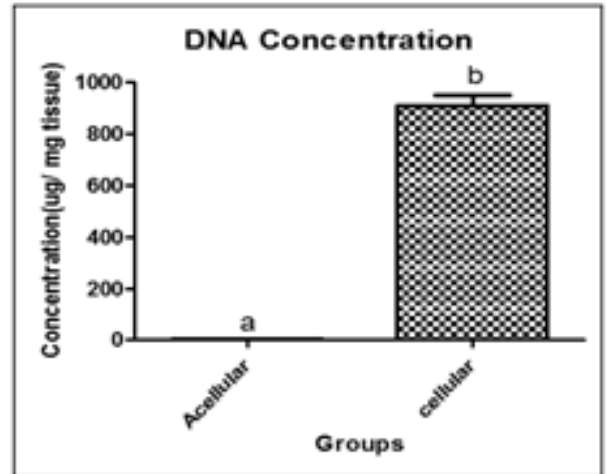

C

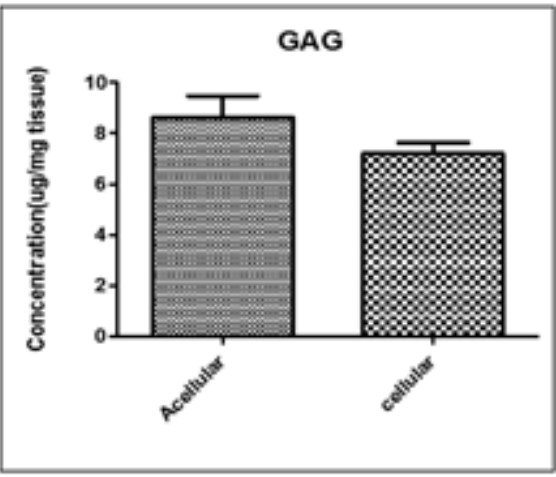

D
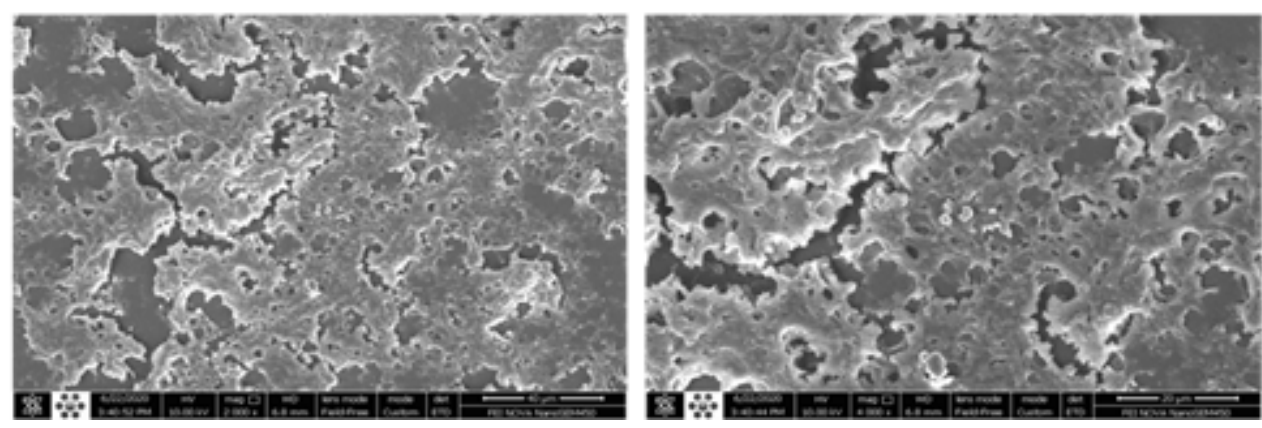

Figure 2

Histological evaluation of the testis after SDS-based decellularization process. A) H\&E staining evidenced preservation of structure. Alcian blue and Masson's trichrome staining showed the presence of GAGs. Scale bar, $100 \mu \mathrm{m}$. B) DNA quantification manifested remarkable cell eliminated by decellularization procedure compared to the normal testis. C) GAGs concentration of decellularized testicular tissue was not significantly altered in comparison with normal tissue. D) SEM assessment of decellularized testicular tissue. The results are presented as means \pm SD. different letters: Significant difference with other experimental group $(p<0.05)$. 
A)

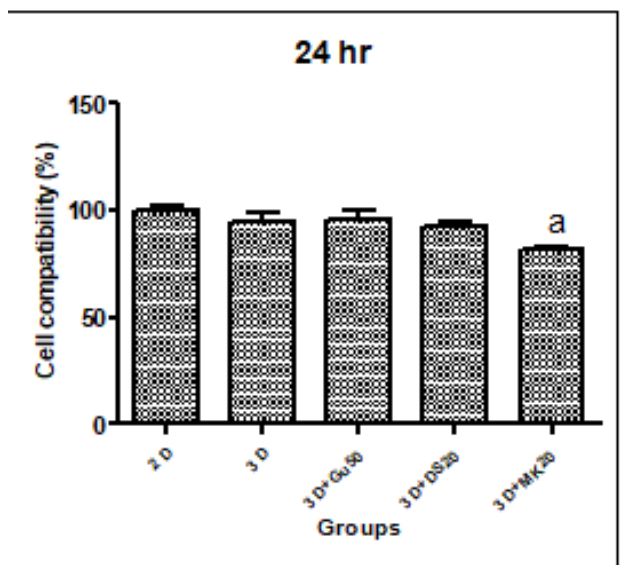

B)

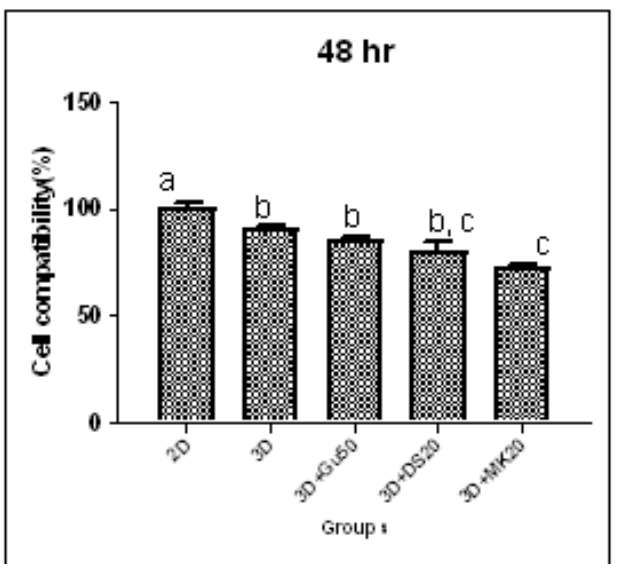

C)

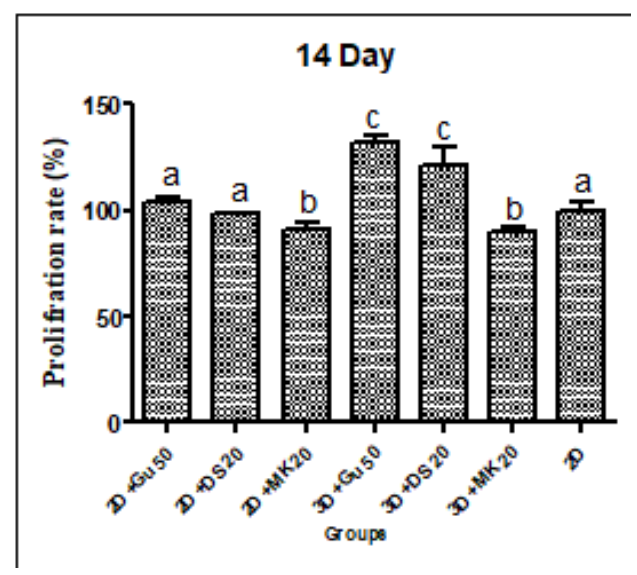

Figure 3

Cell compatibility assay of SSCs in different experimental groups after A) $24 \mathrm{~h}$. and B) $48 \mathrm{~h}$. C) Proliferation rate of SSCs on 3D and 2D culture after 14 days cultivation in different culture media. MTT assay represents the toxicity effect of scaffold during $24 \& 48 \mathrm{~h}$ culture of SSCs. Forth teen days after SSCs cultivation in 2D and 3D condition into different medium indicates a cell proliferation in 3D culture medium treated by Gu50 and DS20. Although, the results showed a proliferation rate decrease in 3D culture medium treated by MK20. SSC: Spermatogonial Stem Cell; DS: D-Serine; Gu: Glutamic acid; MK: MK-801. Different letters: Significant difference with other experimental groups $(p<0.05)$.

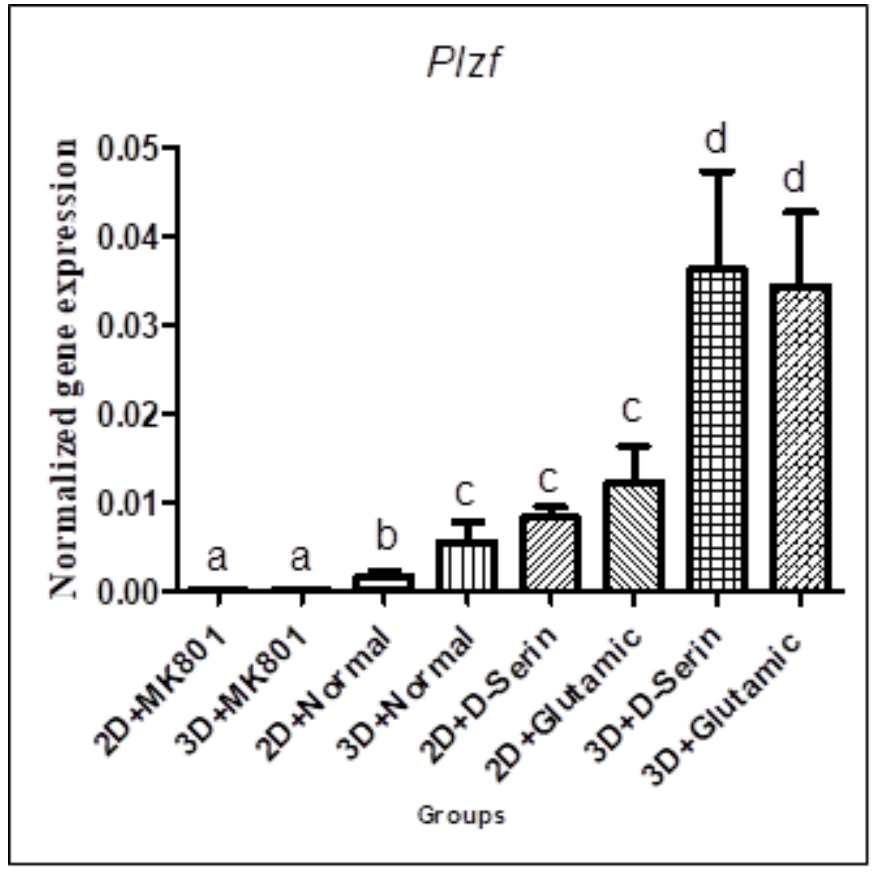

Figure 4

Expression level of Plzf in 2D and 3D cultured SSCs with $20 \mathrm{mM}$ D-Serine and $50 \mathrm{mM}$ glutamic acid or MK-801. The real time PCR results were normalized to a reference gene ( $\beta$-actin gene). The letters shown in the figure 4 have statistically significant differences $(p<0.001)$. SSCs: Spermatogonial Stem Cell; MK: MK-801. The results are presented as means \pm SD. 

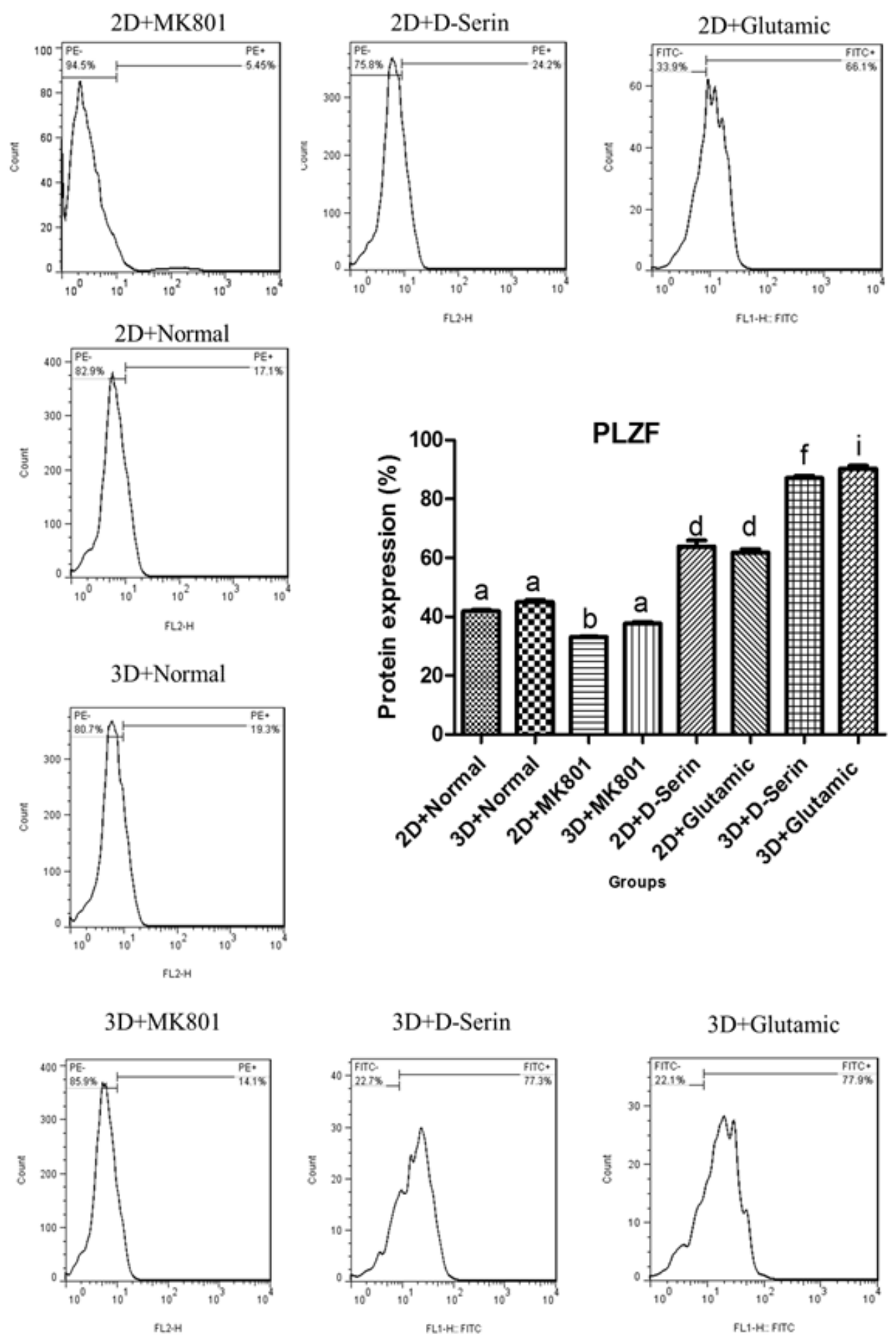

\section{Figure 5}

Protein level of Plzf in 2D and 3D cultured SSC with 20mM D- serine and $50 \mathrm{mM}$ glutamic acid or MK801. Intensity of FITC dye was used for analyzing of Plzf protein in comparison with isotype control sample by flow cytometric assay. The different letters shown in the figure 5 have statistically significant differences $(p<0.001)$. SSCs: Spermatogonial Stem Cells; DS: D-Serine; MK: MK801. The results are presented as means \pm SD. 